seen to be responding to the new consumerism and to the political shift to the right with its suspicion of the professions and their privileges. So evolution must continue; much can be done even without a new parliamentary bill.

Nevertheless, given the present workload of both the members and the staff, has the GMC the time, the resources, or the disinterestedness to do the research and to introduce far reaching changes? There is a strong case for an independent rather than an internal inquiry, and a further factor in its favour would be the likely support from both the profession and the public. Such an inquiry must be set up by doctors: not only does self regulation remain the hallmark of any profession, but doctors, patients, and the community all stand to lose far more than they would gain by the intrusion of, say, the government into the process. And, united as doctors are at present by the discussions on Mr Clarke's white paper, it would be wise for the whole profession (particularly, for example, the BMA and the conference of medical royal colleges and faculties) to be seen to be setting this up itself as soon as possible, together with representatives of other academic and lay interests.

So far as the GMC is concerned such an inquiry should concentrate on how the mass of problems it has to deal with can be tackled by ordinary practising doctors who are part time members. Urgent reform is surely needed when a dedicated president is spending $30-40$ hours a week on what is supposed to take only two days. But the inquiry should not neglect one essential aspect of the GMC: the power of its secretariat. As Hennessey has shown in his recent book on the civil service, ${ }^{15}$ it is a mistake to hold administrative wings entirely responsible for the ills of larger bodies - secretariats contain loyal, dedicated staff, unable to answer back, who are usually working under great difficulties. Nevertheless, Hennessey quotes Professor David Herderson's description of the civil service as "ponderous, ritualised, secretive, and highly unreliable in its results." Smith, who emphasised the difficulties under which the GMC Secretariat was working, was uncertain about how much power resided in the secretariat. Given, however, that all the council members are part time, it is probably considerable, and anyway the office is likely to set the prevailing tone of operations - in particular, the poor communications, both internally and externally.

Hence, several questions need answering. How can one of the principal functions of the GMC-surveillance of undergraduate medical education - be properly served with only three members of staff? Should it be allowed its wish to take over the supervision of postgraduate education? Is there a case for recruiting outside experts to the secretariat at senior levels - for example, in medical education or computing and information systems - as Hennessey recommends for the civil service? Could the system become more human and acceptable to the profession if doctors were taken on as members of the staff, an admirable feature of the defence bodies and the BMA and recommended for the GMC by the BMA in its evidence to the Merrison inquiry? How can it be ensured that the new press officer is allowed to build up a relation of trust with the media and the public? And how can it be got across to doctors that their subscriptions are well spent, in the interests of the profession and of the public?

The case for action, in the BMF's view, is clear. Nevertheless, any altered GMC will be more expensive, entailing higher subscriptions from individual doctors. They should be prepared to pay these, both because the benefits will be correspondingly greater (to doctors and to society) and because they need to keep regulation of the profession where it belongs - with the profession.

Editor, $B M \mathcal{F}$

STEPHEN LOCK

1 Smith R. The day of judgment comes closer. Br. Med f 1989;298:1241-4

Smith R. 1978 and all that. Br.Med f 1989;298:1297-1300.

Smith R. Medical education and the GMC: controlled or stifled? Br.Med $\mathcal{f}$ 1989;298:1372-5.

Smith R. Overseas doctors: diminishing controversy. Br Med F 1989;298:1+41-4.

Smith R. Discipline I: the hordes at the gates. Br.Med f 1989;298:1502-5.

Smith R. Discipline II: the preliminary screener-a powerful gatekeeper. $\mathrm{Br}$ Med $\mathcal{f}$ 1989;298: 1569-71.

Smith R. Discipline III: the final stages. Br.Med f 1989;298:1632-4.

8 Smith R. Dealing with sickness and incompetence: success and failure. Br Med f 1989;298:1695-8.

Smith R. The council's internal problems. Br. Med f 1989;299:40-3.

10 Kilpatrick R. Profile of the GMC : portrait or caricature? Br.Med f 1989;299: 109-12.

11 Committee of Inquiry into the regulation of the medical profession. Report. London: HMSO, 1975. (Cmnd 6018.) (Merrison report.)

BMA. BMA's Evidence to Merrison Inquiry. Br.Med J Supplement 1933;1:159-75.

13 O'Donnell M. Crisis of confidence. World Medicine. 22 November 1972;5-7.

14 Lowe R. Leading article in The Times 1852. Cited by Hennessey P. Whitehall. London: Secker and Warburg, 1989.

15 Hennessey P. Whitchall. London: Secker and Warburg, 1989

\title{
The computer will see you now
}

\section{Research and clinical uses of computerised assessments must be distinguished}

The development of inexpensive self administered computerised assessments means that patients may soon find themselves at a computer terminal before seeing their doctor face to face. ${ }^{1}$ Doctors in all specialties are faced with this potential revolution in medical practice.

Psychiatrists might have been expected to be among the last to apply an automated method of collecting clinical information, but there are many self administered computerised assessments of psychiatric disorder ${ }^{2}-$ and their acceptability and ease of use have been shown convincingly. ${ }^{3-7}$ They may be completed by unsupervised patients after only brief explanation, ${ }^{3}$ and unlike pencil and paper questionnaires they avoid redundant inquiry as the presentation of questions depends on previous answers. There are indications that socially undesirable responses are more likely to be divulged-for example, people admit drinking more alcohol to a computer than to a trained interviewer. ${ }^{8}$

The main concern is whether these automated assessments provide valid measures of mental disorder. Validity is a complex subject, and rather than asking, "Is this test valid?" it is better to ask, "Valid for what?" Research and clinical uses must be distinguished. Lewis et al compared their computerised system for assessing minor psychiatric disorder with a research interview by a psychiatrist, claiming that the measure is probably as valid for some research purposes as current standardised interviews. ${ }^{3}$ Greist $e t$ al have also shown adequate agreement for some psychiatric diagnoses but not for others.

The research applications of computerised assessments are considerable. There is no observer bias, and data are stored directly on computer disk with savings in labour costs and the tedium of coding results. Computerised assessments should be especially useful to medical researchers who require detailed psychiatric assessments but wish to avoid expensive standardised interviews.

The clinical use of these assessments is more doubtful. 
Some promotional claims are excessive-for instance, "the time required... to conduct an initial diagnostic interview can be reduced from $1-1.5$ hours to approximately 15 minutes" (Blouin AG, Walsh G, Perez E, Computerized DSM-III diagnosis: C-DIS, Ottawa Civic Hospital). There are even claims that one system "can diagnose schizophrenia in five minutes." There is, however, only modest agreement (kappa values from 0.06 to 0.60 ) between diagnoses on the basis of clinical assessment and of computer assessment, ${ }^{59}$ leading to the conclusion that "it would be inappropriate to use [the computer] alone for diagnosis." 59

A puzzled disappointment has arisen among proponents of these assessments because other doctors have not used them. ${ }^{10}$ The reluctance has been attributed to conservatism and apprehension about information technology, which ignores doubts about the clinical validity of the assessments. Also many oppose computerised assessments because they fear a loss of human communication ${ }^{11}$ and believe that the only motive for using them is to reduce costs. These fears are fuelled when enthusiasts call their systems "interviews" $+57-$ in fact they are simply multiple choice questionnaires, albeit in an elegant format. A medical interview is more than a means of gathering information and of diagnosis; rather "it is an interaction between two people and ought to be as meaningful for the person who answers the questions as for the questioner." 12 Most clinicians will not use these assessments until they have been carefully evaluated.

Computerised assessments have an undoubted role in research and may prove to be of clinical value in collecting routine information, freeing doctors to use their time with patients more constructively. But satisfaction with treatment, compliance, and non-specific healing effects are all closely related to the doctor-patient relationship. In medicine the consultation "is the beginning of therapy," 12 and computerised assessments will not be useful if they are allowed to interfere with communication between patients and their doctors.

ANTHONY J PELOSI

Research Fellow in Clinical Epidemiology

GLYN LEWIS

Research Worker

General Practice Research Unit,

Institute of Psychiatry,

London SE5 8AF

1 Lieff JD. Computer applications in psychiatry. Washington: American Psychiatric Press, 1987

2 Hedlund JL, Vieweg BW, Cho DW. Mental health computing in the 1980s: II. Clinical applications. Computers in Human Services 1985;1:1-31.

Lewis G, Pelosi AJ, Glover E, et al. The development of a computerised assessment for minor psychiatric disorder. Psychol Med 1988;18:737-45.

4 Blouin AG, Perez EL, Blouin JH. Computerized administration of the Diagnostic Interview Schedule. Psychiatry Res 1988;23:335-44.

Greist JH, Klein MH, Erdman HP, et al. Comparison of computer-and-interviewer-administered versions of the Diagnostic Interview Schedule. Hosp Community Psychiatry 1987;38:1304-11

6 Long PW. Decisionbase: computerized psychiatric history and diagnosis. Vancouver: Phillip W Long, 1988.

Carr AC, Ghosh A, Ancill RJ. Can a computer take a psychiatric history? Psychol Med 1983;13 $151-8$.

8 Lucas RW, Mullin PJ, Luna CBX, Mcllroy DC. Psychiatrists and a computer as interrogators of patients with alcohol related illnesses: a comparison. Br f Psychiatry 1977;131:160-7.

9 Mathisen KS, Evans FJ, Meyers K. Evaluation of a computerized version of the Diagnostic Interview Schedule. Hosp Community Psychiatry 1987;38:1311-5.

10 Schwartz MD. Using computers in clinical practice. Psychotherapy and clinical applications. New York: Haworth Press, 1984

11 Ber R. Time saved for what? Lancet 1987;i:1515.

12 Edwards G. The treatment of drinking problems: a guide for the helping professions. London: (Grant McIntyre, 1982

\section{The course of anorexia nervosa}

\section{About one in 30 die, and half recover fully after six years}

William Gull, the originator of the term anorexia nervosa, thought that the outcome of the syndrome was generally favourable. ${ }^{1}$ In contrast, the first systematic follow up studies of 30 years ago produced alarming results: at least $15 \%$ of patients died, most had persistent symptoms of eating disorder, and less than a fifth recovered fully. ${ }^{23}$ Since then the question of what happens to patients with anorexia has become increasingly clouded - largely because data have been gathered from different clinical settings. Small samples of patients have been used, and follow up has varied in length. But recent data have begun to make things clearer.

Although several studies have reported mortality in anorexia nervosa to be below $5 \%,{ }^{+6}$ deficiencies in their methods (including failure to report standardised mortality ratios) make interpretation difficult. A more comprehensive assessment of 481 patients over 10 years has shown a crude mortality for anorexia nervosa of just over $3 \%^{7}$-confirming the recent trend to lower mortality. The standardised mortality ratio for this group showed a sixfold increase, and that for the patients with the lowest weight $(<35 \mathrm{~kg})$ a 15 -fold increase. The predictors of death were a patient's lowest reported weight and repeated hospital admissions. Half of those who died killed themselves through overdoses, which challenges the earlier view that death in anorexia nervosa is always a direct consequence of malnutrition. ${ }^{3}$ An important finding was that the standardised mortality ratio increased for at least eight years after referral. This is consistent with two smaller long term studies, which showed that deaths in the chronically ill subjects continued at a high rate for 20 years after the initial consultation ( $\mathrm{R} \mathrm{H}$ Ratnasuriya et al, unpublished data). ${ }^{8}$

Recent studies found that after a minimum follow up of four years a quarter of patients had persisting severe problems with weight and menstruation; another quarter had improved; and half had fully recovered..$^{+6}$ Eventually, still more patients recover: a study in Sweden with a long follow up found that a quarter of patients had recovered after three years, half after six years, and three quarters after 12 years, but that recovery thereafter was rare. ${ }^{8}$ High rates of depression and psychosocial disturbance have been observed in follow up studies but are difficult to interpret because the studies failed to use standardised assessments or to include comparison populations. Consistent predictors of poor outcome have proved to be elusive, but the lowest weight, the length of illness, older age at onset, and disturbed family relationships seem to be the most constant.

For patients whose weight remains low the course of anorexia nervosa may be further clouded by physical complications. Osteoporosis, perhaps caused by a combination of malnutrition and oestrogen deficiency, tends to reverse with weight gain. ${ }^{9}$ But in patients whose weight remains low in the long term the loss of bone seems to be cumulative: pathological fractures occur commonly after 10 years. ${ }^{10}$ Computed tomography in patients of low weight has shown structural changes to the brain - ventricular and sulcal enlargement. ${ }^{112}$ Because weight gain does not reverse the ventricular enlarge- 